\title{
The Design of Demand Teaching Mode based on the Pattern of Hierarchical Teaching Model
}

\author{
Peng Xufu ${ }^{1,3, a^{*}}$, Wang Hongli ${ }^{1,2, b}$ \\ ${ }^{1}$ College of Computer Science and Technology, Hubei Normal University, China 435002 \\ ${ }^{2}$ College of Educational Science, Hubei Normal University, China 435002 \\ ${ }^{3}$ College of Arts and Science, Hubei Normal University, China 435000 \\ apengxufu@163.com, b754058066@qq.com \\ * The corresponding author
}

Key words: Teaching mode; layers model; architecture; functional description; demand mode

\begin{abstract}
In view of the present chaos, the authors describe the teaching mode and the fuzzy relationship between modules inside the teaching mode, studies and builds the pattern of 'Four, Five' hierarchical teaching model. With the description of logic layer, conceptual layer, application layer and implementation layer, the authors present the logic hierarchical relationships between the teaching modes and further display functional requirements of every module, such as teaching management, organization, knowledge imparting, knowledge display and teaching method. According to the model, the authors design the instance of demand teaching mode. This model well solves the chaos description of long-term teaching model.
\end{abstract}

\section{Introduction}

Under the new information technology environment, education experts and scholars have done various aspects of research and discussion for new teaching model, which are conducive to the cultivation of innovative talents. For example, Reference [1] introduced computer courses teaching model from five aspects, which consisted of teaching process, basic type, teaching environment, teaching evaluation and research. Reference [2] examined the characteristics and advantages of computer courses teaching pattern under the network environment. Reference [3] investigated the way of building inquiry-based classroom teaching pattern in colleges and universities. Reference [4] studied the reform of computer courses teaching model from the aspect of the discipline competition. Reference [5] studied the way to structure incorporate model of classroom teaching. Reference [6] observed the reform and innovation of computer class teaching model. Reference [7] explored the method to establish integrated classroom teaching mode. Reference [8] analyzed the characteristic of MOOC(Massive Online Open Course).

Although views putted forward by above studies are creative and practical, these studies discretely published their research views about teaching models from different angles, aspects and links. No one has came out a comprehensive, reasonable, global and complete teaching model to meet the requirement of talent training. Therefore, the teaching mode lacks of scientific, systematic, overall and integrated analysis. This topic will research to build a pattern of teaching model.

\section{Analysis and Construction of Teaching Model Architecture}

Design of 'Four, Five' Hierarchical Teaching Model Architecture. The four layer structure of the pattern of 'Four, Five' hierarchical teaching model respectively consists of logic layer, conceptual layer, application layer and implementation layer. Five function modules consist of the teaching management mode, organization mode, knowledge imparting mode, knowledge display mode and teaching method mode. 
Logic layer of the teaching model is the elaboration of education theory and the description of the teaching evaluation standard of each link. Conceptual layer is to define and classify the function of five modules in the teaching mode. The function of application layer is to describe the concrete application of teaching model, which is the main part of the teaching model design. The function of implementation layer refers to design and implement each link in the concrete application. Its architecture is shown as Figure 1.

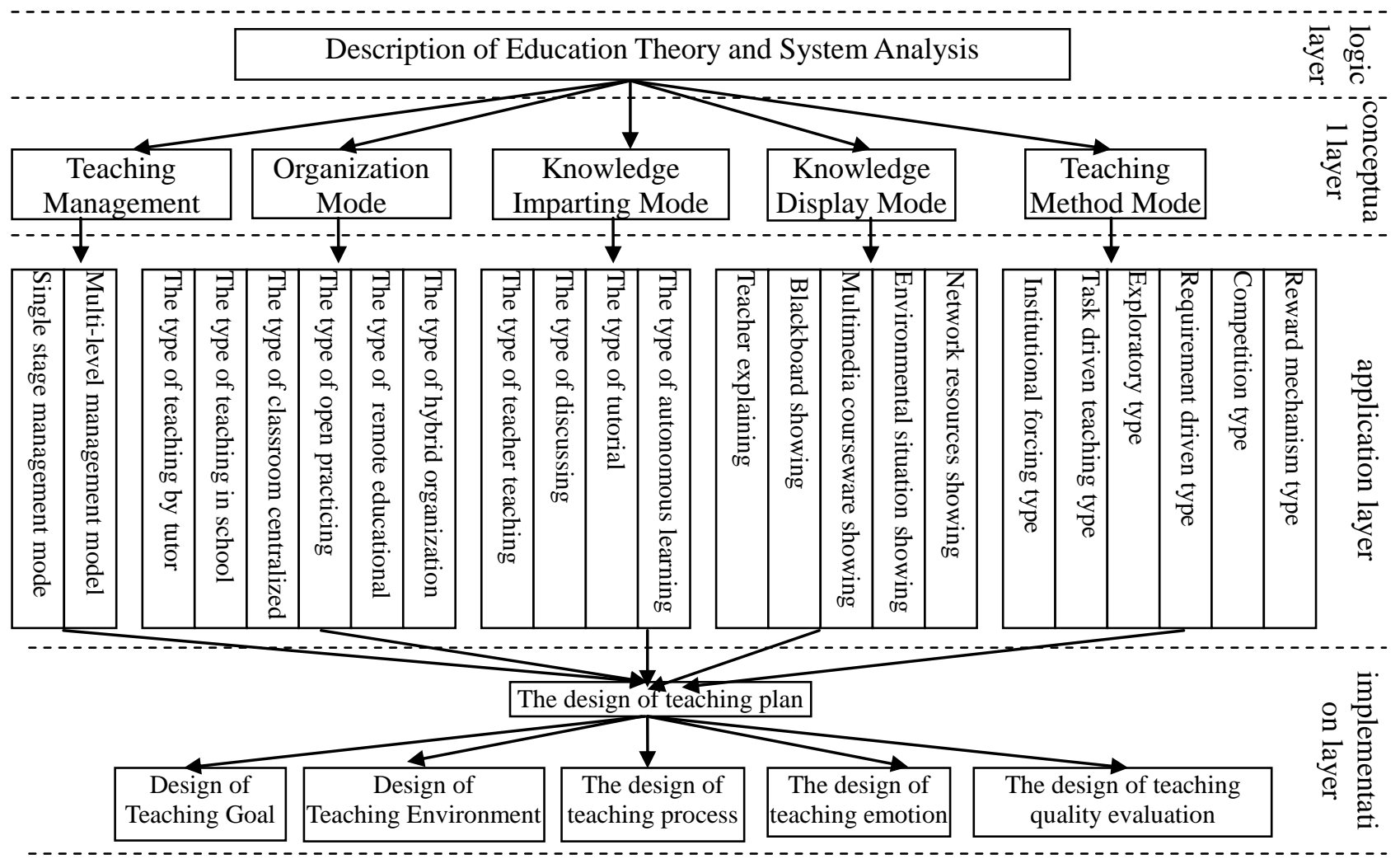

Figure 1 Architecture of 'Four, Five' Hierarchical Teaching Model

Functional Description of the Five Modules of Conceptual Layer. The five function modules of teaching model includes teaching management mode, organization mode, knowledge imparting mode, knowledge display mode and teaching method mode. The function of each mode is introduced as follows.

Teaching Management Mode. Teaching management mode refers to the way that the education administrative department manages and organizes the teaching, which consists of single stage management mode and multi-level management mode. The modern private training school is also a single-stage management mode. National formal education institution is the multi-level management mode. Every organization has its corresponding responsibilities. The duty of teaching management mainly includes the formulation and implementation of teaching management system, teaching affairs management, personnel management, information management, teaching quality assessment and monitoring and the organization and implementation of education theory.

Teaching Organization Mode. Historically, teaching organization mode haS the type of teaching by tutor, teaching in school, classroom centralized, open practicing, remote educational and hybrid organization.

Knowledge Imparting Mode. Knowledge imparting mode refers to the way teachers impart knowledge to students and the way students acquire knowledge. According to different transference ways, this mode can be mainly divided into the teacher teaching type, the discussing type, the experiment demonstration type, and the tutorial and autonomous type (independent learning, 
independent experiment and practice). The advantages and disadvantages of knowledge-transference mode have been discussed in many literatures and will not be repeated here.

Knowledge Display Mode. Knowledge display mode emphasizes the media which is used by teacher to show knowledge to students. This mode can be divided into teacher explaining type, blackboard showing type, multimedia courseware showing type, and environmental situation showing type and network resources showing type.

Teaching Method. Teaching method is an abstract model which is an integral part. It emphasizes teaching organization, knowledge transfer, the skills and procedures of knowledge displaying.

\section{Advantages of 'Four, Five' Hierarchical Teaching Model}

The structure of 'Four, Five' hierarchical teaching model makes people well understand the teaching mode, its advantages are as follows:

(1) Propose a hierarchical and scientific teaching mode to solve the problem that people feel confused to describe the teaching model.

(2) Describe the inner link between the various modules in the form of hierarchical classification, which is advantageous to experts and scholars to carry out scientific research about teaching mode on each link the module. Form a new education theory to promote the cultivation of applied, engineering, research and innovative talent.

(3) It is advantageous for education managers to develop more scientific management system and clearer evaluation standard of teaching quality evaluation system.

(4) Clear model structure provides model basis for experts to build a new teaching mode, which is helpful for people to build clear structure teaching mode.

(5) 'Four, Five' hierarchical teaching model is conducive for evaluation experts to do systematic, scientific, overall, integrity analysis and evaluations about the new teaching model.

\section{Specific Case - Design of Demand Motivation Teaching Mode}

Based on the "Four, Five" hierarchical teaching model, the authors introduce the way to construct the mode of demand motivation teaching.

Construction of Demand Motivation Teaching Mode's Logic Layer. According to the talent quality needed by the construction of social economic and the need of students' development, such as social demand, job requirements, vocational skills requirements, qualifications requirements, life pursuit and so on. Based on the requirement of the talent, it will stimulate students' learning motivation, cultivate students' interest in learning, guide students to explore scientific problems and acquire the knowledge of scientific, enhance the level of professional skills, and improve their ability to solve the problem of science to achieve the training goal of innovative talents in different levels.

\section{Construction of Demand Motivation Teaching Mode's Application Layer}

The Mode of Teaching Management's Design. Education administrative management departments at all levels should design rules, regulations and teaching quality evaluation standards for the mode of demand motivation teaching.

The Mode of Teaching Organization's Design. According to the different characteristics of subjects, different natures of course and different students, people should design the mode of teaching organization neatly. For example, the mode of teaching organization is to combine the model of teaching in class with the mode of open practice and the mode of distance education teaching, and finish theoretical teaching and practical skills training at the same time in the experiment class, which could improve students' learning efficiency and learning interests.

The Mode of Knowledge Transfer's Design. According to the characters of computer professional courses and the requirement of innovation personnel training, the teaching of computer 
knowledge should give priority to the way that teacher guide students autonomous learning. For example, according to qualities and skills of information technology talent, the knowledge of $\mathrm{c}++$, JAVA. NET, web design and production, computer software and hardware maintenance and other professional skills should be taught clearly, arrange students to independently study after class, and organize group discussion and individual coaching on a regular basis.

The Mode of Knowledge Display's Design. Due to characteristics of computer knowledge, such as strong practicality and operationality, this paper uses PowerPoint for teaching, and it is unfavorable for students to master knowledge. Thus, the multimedia courseware demo and network resources must be used.

Of course, the choice of knowledge display mode should be based on the characteristics of different curriculum knowledge, and the author will not introduce them one by one.

The Design of Teaching Method. The teaching method of demand motivation teaching mode can be mainly described as that it treats demand as its target, treats motivation as its power and combines competition, rewards and task driven teaching methods. All of these could excavate students' learning motivation, stimulate students' interest, and improve the teaching effect and teaching quality.

The Design of Demand Motivation Teaching Mode's Teaching Plan. According to the design requirement of the application layer' five function module, demand motivation teaching mode should be detailed design its teaching objectives, teaching environment, teaching process and teaching emotion. Lots of literatures have mentioned this in paper, so it will no longer repeat here.

\section{Conclusion}

The design of 'Four, Five' hierarchical teaching model can well solve the problem that the confused descriptions of teaching model because of lacking scientific teaching model for a long time. Based on this hierarchical teaching model, experts and scholars could build and evaluate new teaching mode scientifically, systematically and comprehensively. Of course, it is just the early period of the research work about teaching mode. Next, the author will build perfect teaching pattern instance, such as the pattern of tutorial, the pattern of exploring question, the pattern of task-driven, the pattern of competition and the pattern of rewards motivating to do the basic work for the education teaching theory research.

\section{Acknowledgements}

This research was supported by innovative team of excellent young-middle-aged, universities in Hubei province (T201430), Hubei province education science "twelfth five-year" plan project (2013B112), the key discipline of Hubei province special education funds.

\section{Reference}

[1] Zheng Shiyu, Ma Changli, Yang Sanping, Introduction to Computer Technology Teaching Method. Beijing:Tsinghua university press, 2011.

[2] Wang Ringfeng. The Discovery Service of The Computer Courses Teaching Model Based on The Network Environment [J].Science and Technology Information, 2013, (19): 213.

[3] Wang Chunyan, The Research of The Inquiry-based Classroom Teaching Mode Reform in the University. Exploration of Higher Education.2014, (4), pp.131-138.

[4] Xue Huantang, Niu Qingli. The Research and Study of Computer Courses Teaching Model Based On The Discipline Competition. Henan Science and Technology. 2014, (3), pp. 264-264. 
[5] Wang Xiaoli. The Reform of Computer Self-efficacy and Economic Class Teaching Mode in Development of Information Technology. Science and Technology Innovation Herald, 2014(20), pp.112-113.

[6] Wang Xinhao, Jiang Hui, Wang Ying. The Reform and Innovation of Computer Courses Teaching Model about the Major of Information Management and Information Systems. Modern Enterprise Education, 2013(5), pp. 208-209

[7] Li Xiaoqin. Introduction to The Reform Of Integrative Teaching Model In The Application Of Computer Courses. Science and Technology Consulting. 2014(9), PP. 68-69.

[8] Yu Minhong. MOOK: The Educational Revolution Benefits To Everyone [EB]. http://sike.news.cn/id=218567388 